\title{
Assessment of Medicines Cold Chain Storage Conformity with the National Requirements in Governmental Health Care Facilities of Nekemte Town, Western Ethiopia
}

Ginenus Fekadu*, Gadise Merga and Mohammed Gebre

Department of Pharmacy, Insitute of Health Sciences, Wollega University, Ethiopia

\begin{abstract}
Background and objective: Cold chain' is the system of transporting and storing vaccines within the safe temperature range of $2^{\circ} \mathrm{C}$ to $8^{\circ} \mathrm{C}$. Evidence from studies conducted in different countries indicate that good vaccine practices are lacking even in developed and still developing countries. Limited research has been carried out in Ethiopia with regard to cold chain management of vaccines. Thus, this study aimed to assess medicines cold chain storage conformity with the national necessities in public health facilities of Nekemte town.
\end{abstract}

Methods: A facility based cross-sectional study design was employed in governmental health care facilities of Nekemte town from June to July, 2018. A face to face interview using semi-structured questionnaires was used to collect primary data among all health Workers. The collected data was entered and analyzed using SPSS V.20.

Result: From the total of 99 study participants $55.5 \%$ were males. Among all the respondents' more than half $(59.6 \%)$ were ever attended training on storage, distribution and handling procedures of cold chain medicines. Even though the national guidelines recommends the storage temperature of most vaccines is between $+2^{\circ} \mathrm{C}$ to $+8^{\circ} \mathrm{C}$, only about $44(44.4 \%)$ respondents were practicing the recommended temperature range for most cold chain medicines stored in refrigerators. Majority, $69(69.7 \%)$ of the respondents said that storage device equipped with thermometers. Similarly the study indicated that most of the health care facilities $(56.25 \%)$ had a thermometer in refrigerator. Temperature monitoring being recorded was not statistically significant difference with the compliance with storage temperature $(P=0.08)$

Conclusion: The study revealed that less than half of the respondents did not comply with storage temperature as per the national standard. Indeed, all these affect the quality of temperature sensitive medicines and risk for public health. Health care facilities should develop and adhere to detailed written routine vaccine storage and handling plan.

Keywords: Cold chain; Storage; Conformity; Nekemte; Ethiopia

Abbreviations: EPI: Expanded Program on Immunization; PFSA: Pharmaceutical Fund and Supply Agency; WHO: World Health Organization

\section{Introduction}

Cold chain is the system of transporting and storing vaccines within the safe temperature range of $2^{\circ} \mathrm{C}$ to $8^{\circ} \mathrm{C}$. The chain begins with the refrigerator or freezer at the vaccine manufacturing plant, vaccine distributor and then to the provider's office (immunization clinic) and ends with the administration of the vaccine to the recipients [1]. Health facilities in developing countries are supposed to maintain the cold chain to ensure that temperature sensitive medicines reach consumers in good quality $[2,3]$.

The cold chain system comprises of three major elements: personnel, who use and maintain the equipment and provide the health service; equipment, for the safe storage and transportation of vaccines; and procedures, to manage and control the distribution and use of vaccines. Cold chain products are temperature sensitive and lose their potency if they are exposed to temperatures outside the required range of $+2^{\circ} \mathrm{C}$ to $+8^{\circ} \mathrm{C}$ or when exposed to light $[1,2,4]$.

Immunization programs are widely recognized as one of the most effective means of health intervention [5]. Cold chain management can enhance the quality, safety and efficacy of an immunization program [6]. Vaccines are biological products that lose their potency over time and this will result in reduced immune responses and inadequate protection against disease [7].
Once the potency of a vaccine is lost, it cannot be regained or restored and the vaccine will no longer provide protection against the target disease [6]. The temperature should be read and recorded twice a day on a temperature chart. If the temperature stays outside the safe temperature range or if the fridge tag alarms, then immediate action is necessary [8]. Therefore, competent personnel, effective equipment and efficient procedures are vital parts of the cold chain system [7].

Freezing and subjecting vaccines to heat are the most common reasons for vaccine damage and ultimately, wastage. This emphasizes the importance of the cold chain system within an immunization programme as it ensures that vaccines are maintained at the correct temperatures and thus, guarantees the effectiveness of vaccines in such programs [9]. To ensure the success of immunization programs, it is imperative that nurses ensure the maintenance of vaccines in their

*Corresponding author: Ginenus Fekadu, Department of Pharmacy, Institute f Health Sciences Wollega University, Nekemte, Ethiopia, Tel: +251-917137145; +251-917733383; Fax: +251-576617980; E-mail: ginenusjesus@gmail.com ginenus@wollegauniversity.edu.et

Received November 02, 2018; Accepted November 20, 2018; Published November 28, 2018

Citation: Fekadu G, Merga G, Gebre M (2018) Assessment of Medicines Cold Chain Storage Conformity with the National Requirements in Governmental Health Care Facilities of Nekemte Town, Western Ethiopia. J Bioanal Biomed 10:118-122. doi:10.4172/1948-593X.1000219

Copyright: @2018 Fekadu G, et al. This is an open-access article distributed under the terms of the Creative Commons Attribution License, which permits unrestricted use, distribution, and reproduction in any medium, provided the original author and source are credited. 
Citation: Fekadu G, Merga G, Gebre M (2018) Assessment of Medicines Cold Chain Storage Conformity with the National Requirements in Governmental Health Care Facilities of Nekemte Town, Western Ethiopia. J Bioanal Biomed 10:118-122. doi:10.4172/1948-593X.1000219

original state, through the cold chain system [10]. Many global studies have found that attention to maintenance of correct temperatures during storage and use of vaccines is a challenge for staff. According to these studies challenges that staffs face were due to non-competent personnel managing the vaccines, equipment used for vaccine management not being effective and procedures not being efficient [11-13].

According to the Vaccine Handling and Storage toolkit, vaccines must be stored correctly from the time they are manufactured until the time they are administered to children. The exposure of vaccines to heat or cold can reduce the vaccines potency, thus increasing the risk of children not being protected against vaccine-preventable diseases [14]. A study conducted in eight health districts in Cameroon revealed that the targeted health districts were not compliant with the standard operating procedures. Almost $25 \%$ of health facilities were conducting the expanded program on immunization (EPI) activities without cold chain equipment resulting in a threat to the cold chain for vaccines [15]. When children are immunized with vaccines exposed to inappropriate temperatures they need to be re-vaccinated. Vaccine recalls result in extra doses of vaccines for children, increased costs for providers, damage to public confidence in vaccines and can also be a liability for providers' practices $[5,14]$.

Evidence from studies conducted in different countries indicate that good vaccine practices are lacking even in developed and still developing countries. Examples of these include inadequate temperature monitoring, unreliable equipment and use of incorrect fridges [7,10,13,16-19]. Limited research has been carried out in Ethiopia with regard to cold chain management of vaccines. Thus, this study aimed to assess how cold chain for vaccines is maintained by the health workers in and also it can be used as a reference for others who are interested to conduct similar study.

\section{Methods}

\section{Study area and period}

The study was conducted in selected governmental health facility of Nekemte Town. It is located at 315 Kilometers West of the country's capital city; Addis Abeba. According to the national census of 2017 the projected total population of the Town is 109,192. The Town has 2 governmental Health Centers (HCs), two Hospitals owned by government and additionally there are 51 private clinics and 8 private pharmacies. The study was conducted governmental health care facilities at Bake Jama health center, Cheleleki Health center, Nekemte Referral hospital and Wollega university referral hospital.

\section{Study design}

A facility based cross-sectional study design was employed in in governmental healthcare facilities of Nekemte town from June to July, 2018.

\section{Population}

Source population: The source population for this study was all health workers working in governmental health care facilities of Nekemte town.

Study population: All health workers responsible for managing temperature sensitive medicines was interviewed about their practicesandling of temperature sensitive medicines.

\section{Eligibility criteria}

Inclusion criteria: Health workers working in the facility for more than one month.

Exclusion criteria: Health providers not responsible for managing temperature sensitive medicines.

\section{Study variables}

Dependent variable: Compliance to storage temperature

Independent variable: Professions, availability of storage devices, training, job experience, backup in electricity failure

\section{Sample size determinations and sampling procedure}

Sample size determinations: Sample size was determined using single population proportion formula. While determining a sample size the proportion $\mathrm{P}=0.5$ was considered since there was no similar study done in the area, 5\% significance level and 5\% margin of error. Accordingly, the sample size was calculated as:

$$
n=\frac{\left(\frac{\mathrm{Z} \alpha}{2}\right)^{\mathrm{Z}} p(1-P)}{d^{2}}
$$

Where

n- Is the minimum possible sample size

$\mathbf{Z}_{\text {a/2- }}$ is standard score value for $95 \%$ confidence level for two sides normal distribution

p- Is the proportion health worker's compliance with the national requirements of medicines cold chain storage

d- Is margin of error

$$
n=\frac{\left(\frac{Z \alpha}{2}\right)^{Z} p(1-P)}{d^{2}}=\frac{(1.96 * 1.96 * 0.5 * 0.5)}{0.05 * 0.05}=\frac{0.9604}{0.0025}
$$

$=384.16 \approx 384$

Since the study population is less than 10,000 , by using correction formula

$$
\mathrm{N} \text { final }=\frac{n}{1+\frac{n}{N}} \quad \mathrm{~N} \text { final }=\frac{384}{1+\frac{384}{130}}=96,
$$

Adding non-response rate $5 \%$ the final sample size was $n=101$

\section{Data collection process}

A face to face interview using semi-structured questionnaires was used to collect primary data among all health care Workers. A Semistructured questioner was prepared after reviewing different literatures and it is adopted. English version of the questioners was employing as the data collection tool. A formal document review indicating the aims and study process were provided to the facility to request the facility's permission. After the permission was obtained the data collectors start to facilitate the data collection process ease.

\section{Data quality control}

Pre-test was conducted on $10 \%$ of sample size health professionals working in other facility out of selected areas, to find out the comments about lack of clarity in wording of the questionnaire. It is also collected 
Citation: Fekadu G, Merga G, Gebre M (2018) Assessment of Medicines Cold Chain Storage Conformity with the National Requirements in Governmental Health Care Facilities of Nekemte Town, Western Ethiopia. J Bioanal Biomed 10:118-122. doi:10.4172/1948-593X.1000219

to check for its completeness and clarity. Not a single health care worker was interviewed in front of other health care provider or clients.

\section{Data processing and analysis}

The collected data was entered and analyzed using SPSS V.20. Frequency and percentages are computed to present the descriptive findings. A p-value $<0.05$ will be considered as cut-off point for statistical significance.

\section{Ethical consideration}

Ethical clearance was obtained from the Ethical review board of institute of health sciences of Wollega University. Then the letter of cooperation was obtained from The University and Nekemte town health office. After the purpose of the study was discussed with Health Centers and hospitals Directors, the verbal consent was obtained from the study participants.

\section{Result and Discussion}

A total of 99 respondents with $98 \%$ response rates were obtained in this study. Regarding the respondents about 45(45.5) have 4-7 y work experiences. Among all the respondents' large proportion 59 (59.6\%) were ever attended training on storage, distribution and handling procedures of cold chain medicines. Within the last three years less than one third had once a time the training on storage, distribution and handling procedures of cold chain medicines (Table 1).

\section{Health workers practices in handling medicines cold chain and prerequisites}

Guidelines are important to be followed during handling and storage of medicines. The decision to use the type of the guideline depends on the perspective of the setup as well as the level of country. Most of low and middle income countries use world health organization as there is no well standard guideline for respective country. In our setup there is no regulated guideline to use at health care or hospital level in handling and storage of cold chain drugs. Regulatory guidelines for cold chain storage (which staffs have to follow) are not written in the form of Standard Operating Procedures (SOPs) in our setup. Thus health care professionals use the guideline that fits with their knowledge. Regulatory guidelines for cold chain storage (which staffs have to follow) are not written in the form of Standard Operating Procedures (SOPs) in our setup.

Regarding the guidelines utilization, 60 of the respondents were utilizing the guidelines; majority $33(33.3 \%)$ were using the EPI guidelines for vaccine management while $18(18.2 \%)$ were using WHO's Good Storage Practice. The remaining 9(9.1\%) were using WHO's Good Distribution Practice. About 39(39.4\%) of the respondents didn't know what guidelines they are using for managing the quality management system during your practice. The percentage of health care workers using the guideline was lower as compared to different previous literatures [16-18]. Of those who had guidelines; 43 (43.4\%) ever gone through it to find out proper ways of storage and handling temperature sensitive medicines at their facility up to the point of administration and the rests didn't go through it. Besides, only $24,(24.2 \%)$ of the respondents had said their written instructions describing storage procedures, materials handling and documentation this complies with previous studies $[7,11,16]$. Health care facilities should develop and adhere to detailed written routine vaccine storage and handling plan that is updated annually.

The respondents were also asked what they inspect while receiving

\begin{tabular}{|c|c|c|}
\hline Variables & Frequency $(n)$ & Percent (\%) \\
\hline \multicolumn{3}{|c|}{ Health facilities } \\
\hline Bakejama health center & 13 & 13.1 \\
\hline Cheleleki health center & 20 & 20.2 \\
\hline Nekemte Referral Hospital & 30 & 30.3 \\
\hline Wollega University Referral Hospital & 36 & 36.4 \\
\hline \multicolumn{3}{|c|}{ Sex of the professionals } \\
\hline Male & 55 & 55.5 \\
\hline Female & 44 & 44.4 \\
\hline \multicolumn{3}{|c|}{ What is your profession? } \\
\hline Medical Attendant & 53 & 53.5 \\
\hline Nurse & 40 & 40.4 \\
\hline Pharmaceutical technician & 4 & 4.0 \\
\hline Pharmacist & 2 & 2.0 \\
\hline \multicolumn{3}{|c|}{ How long you have been doing this work? } \\
\hline $0-3$ years & 44.0 & 44.4 \\
\hline 4-7 years & 45 & 45.5 \\
\hline Above 12 years & 10 & 10.1 \\
\hline \multicolumn{3}{|c|}{$\begin{array}{l}\text { Have you ever attended training on storage, distribution and handling } \\
\text { procedures of cold chain medicines? }\end{array}$} \\
\hline Yes & 59 & 59.6 \\
\hline No & 40 & 40.4 \\
\hline \multicolumn{3}{|c|}{ How many times have you attended such a course within last three years? } \\
\hline Once & 27 & 27.3 \\
\hline twice & 24 & 24.2 \\
\hline Thrice & 8 & 8.1 \\
\hline Not Attended & 40 & 40.4 \\
\hline
\end{tabular}

Table 1: Profession, work experience and training status of the respondents in governmental health care facilities of Nekemte town from June to July, 2018.

cold chain product from wholesalers/Pharmaceutical fund and supply agency/PFSA. Accordingly, 65 (65.7\%) inspect expiry date and vaccine vial monitor $26(26.3 \%)$ temperature of cold box and $8(8.1 \%)$ inspects medicine should be in a box with ice packs. They also asked whether vaccines and other cold chain medicines were stored in the same refrigerator. Hence, 77 (77.8\%) responded that as vaccines and other cold chain medicines stored in the same refrigerator and the rests said no. Finally, they asked which items are stored in the cold storage facility. They responded that $71(71.7 \%)$ ice cubes and drinks, 21 (21.2\%) drinks only 7 (7.1\%) ice cubes.

\section{Factors related to fault storage}

Majority 69 (69.7\%) of the respondents said that storage device equipped with thermometers and $30(30.3 \%)$ it was not equipped with thermometers. Even though they have thermometers majority said that the storage device was not furnished with low and high temperature alarms. Similar study indicated that most of the health care facilities (56.25\%) had a thermometer in refrigerator, the temperature was not maintained in the required range (31.25\%) increasing the risk of loss of potency of the vaccines. This was lower as compared to study Ateudjieu et al. in Cameroon [15]. This may due to difference in health care facility, resource and set up policy for this medication (Table 2).

On the other hand, about 44 (44.4\%) the respondents were practicing the recommended temperature range $+2^{\circ} \mathrm{C}$ to $8^{\circ} \mathrm{C}$ for most cold chain medicines stored in refrigerators. Even this was lower as compared to Ateudjieu et al. [15]. This due to poor knowledge and shortage of resources to handle these drugs within the proper temperature range (Figure 1).

About $72(72.7 \%)$ the respondent's said that there had been happen 


\begin{tabular}{|c|c|c|}
\hline Factors & Number & Percent (\%) \\
\hline \multicolumn{3}{|c|}{$\begin{array}{l}\text { What do you think are the underlying factors that lead to fault in storage } \\
\text { conditions at your facility }\end{array}$} \\
\hline Unreliable Power supply & 3 & 3.0 \\
\hline Lack of gas & 14 & 14.1 \\
\hline $\begin{array}{c}\text { Low level of knowledge of health care } \\
\text { providers }\end{array}$ & 62 & 62.6 \\
\hline $\begin{array}{l}\text { Delayed replacement of malfunctioning } \\
\text { Fridge }\end{array}$ & 6 & 6.1 \\
\hline All & 14 & 14.1 \\
\hline \multicolumn{3}{|c|}{ Is temperature monitoring being recorded } \\
\hline Yes & 50 & 50.5 \\
\hline No & 49 & 49.5 \\
\hline
\end{tabular}

Table 2: Factors related to fault in storage conditions at your facility in governmenta health care facilities of Nekemte town from June to July, 2018.

that cold chain medicines in a refrigerator or freezer are not kept under recommended temperature range during storage. But when it happened, 41 (57.7\%) continue to store in cold chain for future use, $14(19.7 \%)$ Stop using and recorded in book for cold chain medicines discarded due to incorrect storage temperature. The rest $16(22.5 \%)$ transfer medicines to nearby facility. These precaution measures are very important so as to safeguard the quality of temperature sensitive medicines for the benefit of the public health [3-6]. They also responded that, $61(62.9 \%)$ there were record of cold chain medicines discarded due to incorrect storage temperature (Table 3).

Factors influencing compliance to storage temperature were counted through observation and Chi-square was used to analyses the Statistical significance (Table 4). Storage device should comply with temperature range of $2^{\circ} \mathrm{C}-8^{\circ} \mathrm{C}$ [3]. The temperature range must be maintained to ensure potency of temperature sensitive medicines. Factors that affected compliance included lack of electricity failure, temperature monitors and job experience of health personnel. All storage devices used for storage of cold chain medicines should have temperature monitoring devices. Other issues towards compliance to storage temperature standards were training, job experience and availability of substitute devices in case of electricity failure though were not statistically significant at 5\% level.

In fact all health facilities surveyed had no automated generators. Hence backup electricity electric power is important [7]. Because majority of health facilities in urban areas used electricity refrigerators, unreliable electricity supply was the major challenge frequently encountered [19]. Temperature monitoring being recorded was not statistically significant difference with the compliance with storage temperature in governmental health care facilities of Nekemte town $(\mathrm{P}=0.08)$ (Table 4).

\section{Limitations}

This study has two major limitations. First, the study was carried out among health professionals working in the public health facilities only. Thus the findings cannot be generalized to all health professionals working in Ethiopia. Second, the study was collected using an interview that might be subjected to recall biases.

\section{Conclusion}

About half of the respondents asked (44.4\%) did not comply with storage temperature as per the national standard. Indeed, all these affect the quality of temperature sensitive medicines and may risk public health and safety. According to the results obtained from survey in this study, two issues contribute to non-conformity of cold-chain storage of medicines with national guidelines. First is technical issue

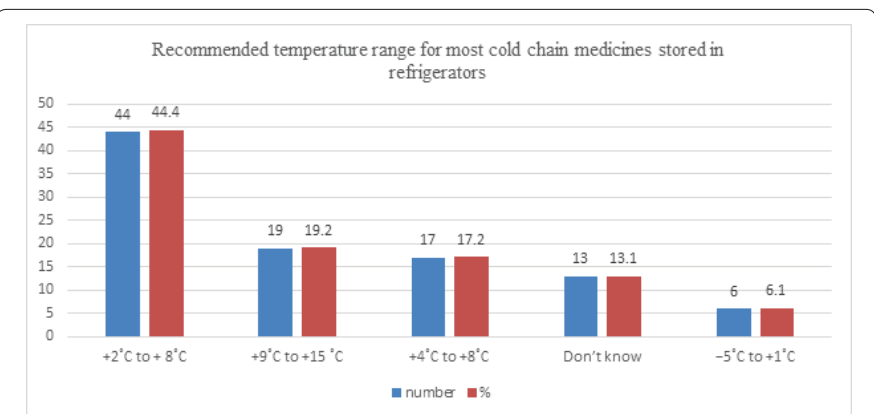

Figure 1: The recommended temperature range for most cold chain medicines stored in refrigerators in governmental health care facilities of Nekemte town from June to July, 2018.

\begin{tabular}{|c|c|c|}
\hline Variables $(n=97)$ & Number (n) & $\begin{array}{c}\text { Percent } \\
(\%)\end{array}$ \\
\hline \multicolumn{3}{|c|}{$\begin{array}{l}\text { Is there any record of cold chain medicines discarded due to incorrect storage } \\
\text { temperature }\end{array}$} \\
\hline Yes & 61 & 62.9 \\
\hline No & 36 & 37.1 \\
\hline \multicolumn{3}{|c|}{ What time do you switch off the fridge in the facility } \\
\hline Evening & 95 & 97.9 \\
\hline Never switched off & 2 & 2.1 \\
\hline \multicolumn{3}{|c|}{ How do you maintain appropriate storage condition in the event of power failure } \\
\hline Gas & 3 & 3.1 \\
\hline Solar & 2 & 2.1 \\
\hline No measures & 92 & 94.8 \\
\hline
\end{tabular}

Table 3: Medicines discarded, time of switch off and means of maintain when power failure, in governmental health care facilities of Nekemte town from June to July, 2018.

\begin{tabular}{|c|c|c|c|c|c|}
\hline \multicolumn{2}{|c|}{} & $\begin{array}{c}\text { Temp range } \\
\left(\mathbf{2}^{\circ} \mathbf{C}-\mathbf{8}^{\circ} \mathbf{C}\right) \\
\text { Compliance }\end{array}$ & $\begin{array}{c}\text { Temp. range } \\
\text { out of } \mathbf{2}^{\circ} \mathbf{C} \\
-\mathbf{8}^{\circ} \mathbf{C} \text { non- } \\
\text { Compliance }\end{array}$ & \multicolumn{2}{|c|}{ Statistical test } \\
\cline { 2 - 5 } & Number (\%) & Number (\%) & $\begin{array}{c}\text { Chi- } \\
\text { Square }\end{array}$ & P-value \\
\hline $\begin{array}{c}\text { Is temperature } \\
\text { monitoring being } \\
\text { recorded }\end{array}$ & Yes & $18(36.0)$ & $32(64.0)$ & 2.916 & 0.088 \\
\cline { 2 - 5 } $\begin{array}{c}\text { Have you ever } \\
\text { attended training on } \\
\text { storage, distribution } \\
\text { and handling } \\
\text { procedures of cold } \\
\text { chain medicines }\end{array}$ & Yes & $26(53.1)$ & $23(46.9)$ & & \\
\cline { 2 - 5 } & No & $15(37.5)$ & $25(62.50$ & 1.311 & 0.25 \\
\hline
\end{tabular}

Table 4: Factors influencing compliance with storage temperature in governmenta health care facilities of Nekemte town from June to July, 2018.

(thermometers) and second is non-conformity on the part of personnel.

Regulatory guidelines for cold chain storage (which staffs have to follow) are not written in the form of Standard Operating Procedures (SOPs). Policy makers of individual healthcare facility need to prepare SOP based on national guidelines. Health care facilities should develop and adhere to detailed written routine vaccine storage and handling plan that is updated annually. It is recommended that health centers should avail standby generators or spare gas supply depending on the electric power availability in the area involved for the cold chain medicines storage. These precaution measures are very important so as to safeguard the quality of temperature sensitive medicines for the benefit of the public health.

Additionally, to enhance quality of cold chain storages: 
Citation: Fekadu G, Merga G, Gebre M (2018) Assessment of Medicines Cold Chain Storage Conformity with the National Requirements in Governmental Health Care Facilities of Nekemte Town, Western Ethiopia. J Bioanal Biomed 10:118-122. doi:10.4172/1948-593X.1000219

a) Compulsory training of staffs involved in cold chain storage facilities.

b) Inspection of cold-storage facilities and auditing of reports on a regular basis by QA/RA department.

c) Routine QC and stability testing by public health quality control for efficacy and safety assessment of vaccines and pharmaceuticals after receipt by healthcare facilities.

\section{Acknowledgment}

The authors would like to thank Wollega University for giving for logistic support and all individuals who rendered help during the study period.

\section{Availability of Data And Materials}

The datasets used and/or analyzed during the current study are available from the corresponding author on reasonable request.

\section{Competing Interests}

No competing interests exist

\section{Authors' Contributions}

GF and GM contribute in the design the study, analysis and write up the manuscript. MG contributed to the design of the study and edition of the manuscripts. All authors critically revised the manuscript and have approved the final manuscript.

\section{References}

1. World Health Organization (2002) WHO Vaccines and Biologicals. Ensuring the quality of vaccines at country level. Guidelines for health staff. WHO.

2. Barbara C (2012) Protecting the cold chain. Pharmacy Connection Spring 19: 33-37.

3. Chiodini J (2014) Safe storage and handling of vaccines. Nurs Stand 28: 45-52.

4. https://www.cdc.gov/vaccines/hcp/admin/storage/index.html

5. Lerman SJ, Gold E (1971) Measles in children previously vaccinated against measles. JAMA 216: 1131-1134.

6. Al-Zamil M, Al-Johar H, Al-Saleh S, Nooh R, Choudhry J (2004) Knowledge and practices of health workers of cold chain. Saudi Epidemiol Bulletin 11: 25-30.

7. Craige L (2008) Keep it cool: Maintaining the vaccine cold chain. Practice
Nurse 36: 19-22.

8. Barker L (2010) The face of South Africa's Expanded Programme on Immunisation Schedule.

9. Ministry of Health (2017) National standards for vaccine storage and transportation for immunisation providers 2017. Ministry of Health, New Zealand.

10. Carr C, Byles J, Durrheim D (2009) Practices nurses best protect the vaccines cold chain in general practice. Australian Journal of Advanced Nursing 27: $35-$ 39.

11. Hipgrave DB, Tran TN, Huong VM, Dat DT, Nga NT, et al. (2006) Immunogenicity of a locally produced hepatitis $B$ vaccine with the birth dose stored outside the cold chain in rural Vietnam. Am J Trop Med Hyg 74: 255-260.

12. Wang L, Li J, Chen H, Li F, Armstrong GL, et al. (2007) Hepatitis B vaccination of newborn infants in rural China: Evaluation of a village-based, out of cold chain delivery strategy. Bull World Health Organ 85: 649-732.

13. Nelson CM, Wibisono $H$, Purwanto $H$, Masyur I, Moniaga V, et al. (2004) Hepatitis B vaccine freezing in the Indonesian cold chain: Evidence and solutions. Bull World Health Organ 82: 99-105.

14. Vaccine Storage and Handling Toolkit (2012) Centre of Disease control and prevention.

15. Ateudjieu J, Kenfack B, Nkontchou BW, Demanou M (2013) Programme on immunization and cold chain monitoring: the status in eight health districts in Cameroon. BMC Res Notes 6: 101.

16. Matthias DM, Robertson J, Garrison MM, Newland S, Nelson C (2007) Freezing temperatures in the vaccine cold chain: A systematic literature review. Vaccine 25: 3980-3986.

17. Wirkas T, Toikilik S, Miller N, Morgan C, Clements CJ (2007) A vaccine cold chain freezing study in PNG highlights technology needs for hot climate countries. Vaccine 25: 691-697.

18. Barnighausen T, Bloom DE, Canning D, O'brien J (2008) Accounting for the full benefits of childhood vaccines in South Africa. S Afr Med J 98: 842-846.

19. Ringo S, Mugoyela V, Kaale E, Sempombe J (2017) Assessment of medicines cold chain storage conformity with the world health organization requirements in health facilities in Tanzania. Pharmacol Pharm 8: 325-338. 